\title{
Интегральная фотоника в радиотехнических системах
}

\author{
С.М. Конторов ${ }^{1, *}$

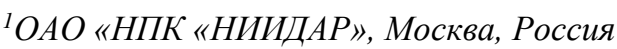 \\ *E-mail: skont86@gmail.com
}

DOI:10.31868/RFL2018.237-238

В современном понимании фотоника означает обширную область знаний, в которой изучаются разнообразные явления, связанные с оптическим излучением. Одним из новых направлений фотоники являетстся сверхвысокочастотная фотоника (радиофотоника), появившаяся в результате интеграции оптоэлектроники и СВЧрадиоэлектроники. Радиофотоника - это одна из наиболее интенсивно развивающихся областей науки и техники в мире, в основе которой модуляция оптического излучения радиосигналом с дальнейшими преобразованиями (фильтрация, усиление, преобразование частоты, диаграммообразование и т.д.) в оптическом диапазоне (см. рисунок 1). Радиофотонные методы позволяют улучшить функциональное построение, а также технические характеристики устройств и систем нового поколения, снять проблемы электромагнитной совместимости, значительно расширить частотный диапазон, на порядки уменьшить потери на распространение сигналов, а также обеспечить высокую стабильность характеристик.

Технологии радиофотоники - это симбиоз технологий СВЧ и микроэлектроники, фотоники и лазерной техники, находящие применение во многих областях (метрология, медицина, радиолокация, радиоастрономия, системы связи различного назначения и базирования (космические, наземные, воздушные, морские) и т.д.) $[1,3,4]$.

Интенсивно создаются радиофотонные интегральные схемы, позволяющие на порядки снизить массогабаритные характеристики, энергопотребление, стоимость, а также значительно улучшить технические характеристики (расширение рабочей полосы до десятков ГГц, реализация многоканальных высокоскоростных систем аналоговой и аналого-цифровой передачи и обработки радиосигналов с частотами до 100 ГГц и более, создание оптоэлектронных генераторов СВЧ сигналов [2], применение широкополосных диаграммообразующих устройств и преобразователей частоты $[4,5,6])$.

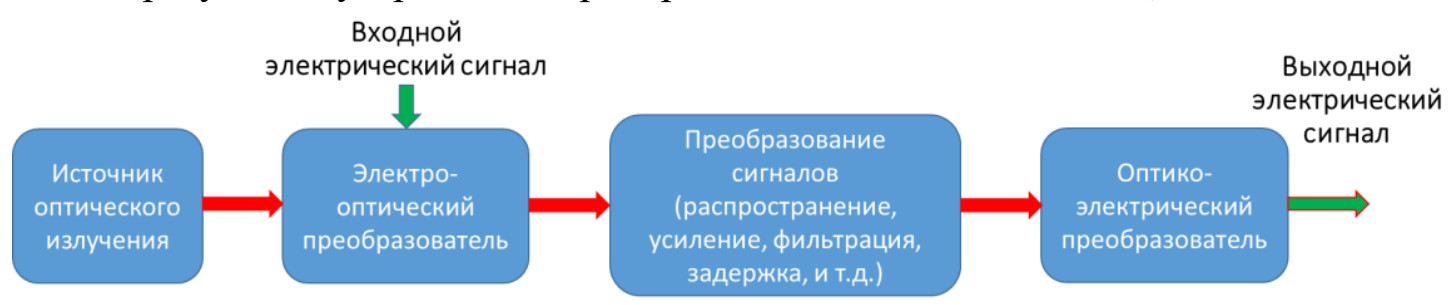

Рисунок 1. Общая радиофотонная структурная схема

В сложных радиофотонных устройствах и системах, где может потребоваться использование до тысяч модуляторов, лазеров и фотодетекторов, перспективным решением является интеграция всех компонентов в микрочиповом исполнении. За рубежом последние 10 лет идет активное развитие технологий интегральной радиофотоники, на сегодняшний день позволяющих интегрировать на одной подложке до тысячи компонентов [5]. Радиофотонные интегральные технологии уже сегодня позволяют объединить как пассивные (устройства ввода/вывода оптического излучения, волноводы, разветвители, объединители, мультиплексоры/демультиплексоры, фильтры, линии задержки, циркуляторы и т.д.) так и управляемые активные (лазеры, фотодетекторы, модуляторы, усилители, фазовращатели, переключатели и т.д.) компоненты на единой подложке (см. рисунок 2). 


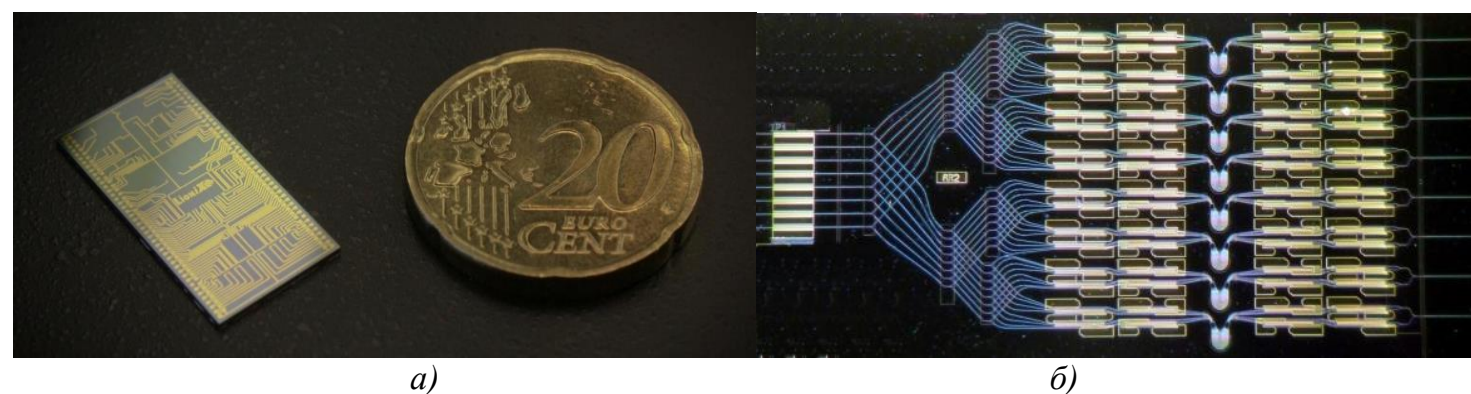

Рисунок 2. Многоэлементные интегральные радиофотонные устройства. а) 16-ти канальное диаграммообразующее устройство и преобразователи частоты [5]; б) - 8x8 диаграммообразующее устройство (136 полупроводниковых оптических усилителей, х1000 элементов на 1 схеме) [7];

Ключевым элементом любого радиофотонного устройства или системы является источник оптического излучения. В качестве такого компонента обычно используется лазер с прямой (десятки ГГц) или внешней (сотни ГГц) модуляцией. В зависимости от применения и схемотехнического решения возможно применение различных типов лазеров: волоконный (высокая мощность, стабильность характеристик), непрерывный (РОС, РБО - низкий уровень шумов, узкая ширина спектральной линии, когерентная радиофотоника), импульсный (лазер с синхронизацией мод - большая частота повторения, синфазность, низкий уровень фазовых шумов), вертикально-излучающие (прямая модуляция до десятков ГГц, низкое энергопотребление, многоканальность в интегральном исполнении) и многие другие. С возрастанием как сложности, так и быстродействия радиофотонных систем возникла естественная потребность к монолитной интеграции компонентной базы радиофотоники на едином кристалле. Поскольку активные и пассивные компоненты возможно формировать по технологиям микроэлектроники, такие системы имеют ряд преимуществ. В настоящее время весь набор компонентной базы радиофотоники реализуется в планарном исполнении на различных технологических платформах [5,8].

Построение функциональной системы на кристалле, по аналогии с монолитной интеграцией компонентов электроники, позволяет создавать радиофотонные интегральные схемы высокой степени интеграции [5,7]. В связи с этим в последнее время возрастает объем разработок и гибридных систем, в которых используется интеграция различных платформ и технологий - InP гетероструктуры для активных элементов (лазер, модулятор, фотодетектор), Si3N4/SiO2 волноводы, SOI для драйверов цифровых устройств, что в конечном счете приводит к созданию полноценных универсальных интегральных фотонных технологий для создания перспективных радиотехнических устройств и систем нового поколения.

\section{Литература}

[1] A. B. Matsko, A. A. Savchenkov et al, J. Lightwave Technology, 28, 3427-3438 (2010).

[2] X. S. Yao, L. Maleki, Electronics Letters, 30, 1525 (1994).

[3] F. Scotti, G. Serafino, A. Capria et al, Nature, 507, 341-345 (2014).

[4] Richard W. Ridgway, Carl L. Dohrman et al, J. Lightwave Technology, 32, 3428-3439 (2014).

[5] David Marpaung, R.G. Heideman et al. Laser \& Photonics Review. 20, (2012).

[6] В.В. Валуев, С.М. Конторов и др., Труды иколы-семинара «Волны-2016», (2016).

[7] Ripalta Stabile, Abhinav Rohit et al, Optics Express 22, pp. 435-442 (2014).

[8] М.Белкин, В.Яковлев, Электроника №3 00143 (2015). 